\title{
The effect of workplace relocation on individuals' activity travel behavior
}

\author{
Francois Spumont \\ Mobilab, University of Luxembourg \\ Francois.Sprumont@uni.lu
}

\author{
Francesco Viti \\ Mobilab, University of Luxembourg \\ Francesco.viti@uni.lu
}

\begin{abstract}
On working days, homes and workplaces can be seen as anchor locations at the heart of daily mobility patterns, as well as being central to an employee's activity pattern. In this study, we investigate how workplace relocation affects the entire daily activity-travel chain. While past research has shown that workplace decentralization is often associated with higher car use for the commuting trip, little is known about the effect on the whole activity travel pattern. Two waves of a two-week travel diary were completed by 43 employees of the University of Luxembourg: one before and one after the relocation of their office. Using descriptive statistics as well as standard deviational ellipses (SDE) theory combined with the results of a clustering analysis showed that workers' activity spaces (represented by the standard deviational ellipses) were significantly modified due to the relocation of a single anchor activity location, i.e., their workplace.
\end{abstract}

\section{Article history:}

Received: November 20, 2016

Received in revised form:

January 17, 2018

Accepted: April 21, 2018

Available online: November 8 , 2018

\section{$1 \quad$ Introduction}

Key life events such as house relocation, having a baby, buying a car, etc. can drastically modify the way individuals travel or perform their activities (van Acker, van Wee, \& Witlox, 2010). As discussed by Schoenduwe, Mueller, and Peters (2015) some life events are endogenous to individuals or the household they belong to (buying a car, house relocation etc.), while others are not (death of spouse/ husband for instance). Recently, Rau and Manton (2016) have underlined the challenges related to understanding the complex interaction processes related to "mobility milestones." Indeed, being recently graduated, buying a car and starting a career are three important life events, but how they interact, and the extent of their direct and indirect effect on travel behavior, is still debated.

Without any doubt, employees' workplace relocation can be considered an important life event, shaping travel behavior and the overall daily activity patterns of individuals. However, because of the non-recurrent nature of such an event and its relative specificity, the effect of workplace relocation on

Copyright 2018 Francois Spumont \& Francesco Viti

http://dx.doi.org/10.5198/jtlu.2018.1123

ISSN: 1938-7849 | Licensed under the Creative Commons Attribution - Noncommercial License 4.0

The Journal of Transport and Land Use is the official journal of the World Society for Transport and Land Use (WSTLUR) and is published and sponsored by the University of Minnesota Center for Transportation Studies. This paper is also published with additional sponsorship from WSTLUR. 
travel behavior has not been extensively studied. Few scientific publications are available, and they vary a great deal in terms of their spatial context and analyzed impacts. While some life events may have a limited effect on individuals' travel behavior and activity pattern, the relocation of employees' workplaces theoretically affects everyone, although not necessarily in an equal manner.

Bell, in 1991, was among the first to scientifically analyze the effect of workplace relocation (workplace suburbanization to be precise) on commuting times, distances and modes. Bell's study (1991) focused on an Australian case study, while Cervero and Landis (1992) discussed the impact of employment decentralization in San Francisco (US) on commuting behavior. Naess and Sandberg (1996) and Hanssen (1995) discussed similar issues in Europe. As also recently highlighted by Vale (2013), there seems to be a consensus that workplace relocation leads to higher car use for the home-to-work trip. Concerning commuting time and distance, no generalization can be reported. While Li, Burke, and Dodson (2016), Cervero and Landis (1992) and Bell (1991) concluded that commuting time was reduced (partly related to a shift to a faster mode) after workplace relocation, other studies, such as Cervero and Wu (1998), showed the opposite.

Despite the impacts of workplace relocation on the commuting trip (time, distance, modal split) and the causes related to such an event having been studied, to the best of the authors' knowledge, there has been no scientific contribution assessing how it affects the entire daily activity pattern. Using an a priori and an ex-ante workplace decentralization cross-sectional survey, Bell (1991) provided some indications on this issue. However, the expectation is that the use of two travel diaries will provide more detailed information since it would provide a full picture of the whole trip-chaining behavior. Understanding how a workplace relocation affects daily activity patterns during working days is of tremendous importance in order to assess and/or estimate changes in behavior (such as travel demand modifications due to changes in activity location of individuals' chained activities (such as shopping)). It also improves understanding of the flexibility of individuals to shift modes of transport in their commuting trips.

Motivated by the above argument, in order to perform our analysis two travel diary data collection phases were implemented. This saw the collection of two-weeks' continuous data, both before and after the relocation of one of the faculties of the University of Luxembourg. The move was from a campus located in the north of Luxembourg City, to the new campus located approximately $25 \mathrm{~km}$ south of the Grand Duchy's capital city.

The next section introduces the scientific literature dealing with workplace relocation while section 3 provides more information on the context. Sections 4 and 5 respectively deal with the specificity of the data set and the methodology used. Section 6 presents the results and, finally, section 7 concludes this paper.

\section{$2 \quad$ Literature review}

Since the second half of the 20th century, workplace decentralization has been considered, by national or regional authorities, as a way to decrease transport demand pressure on city centers ( $\mathrm{Li}$ et al., 2016; Burke, Li, \& Dodson, 2011). Bell (1991) mentions that motivation for companies or public institutions to settle in a suburban area may also be related to the high rental prices of the inner city, the lack of space and a desire to be nearer to the employees' living places.

The relocation of the employee's workplace is, according to Aarhus (2000), affecting four important commuting trips' features: 1) public transport accessibility, 2) road accessibility, 3) parking accessibility and finally, 4) the share of employees with a short distance to work. According to the debated co-location hypothesis (Gordon \& Richardson, 1997), if the majority of a company's workforce is living in a city suburb, workplace suburbanization might reduce the home-to-work distance.

Concerning the commuting mode shift, Vale (2013) recently demonstrated, using data from Lis- 
bon (Portugal), that employees facing workplace relocation try to keep commuting time within acceptable limits. Also, to pursue this goal they may shift to a faster mode (often a car). An increase in car use for the commuting trip was reported in Bell (1991), Cervero and Landis (1992), Cervero and Wu (1998), Aarhus (2000) and Hansen (1995). On the other hand, Vale (2013) pointed out that the magnitude of this modal shift should be analyzed carefully. Indeed, Vale (2013) showed that $73 \%$ of employees faced with workplace relocation did not modify their commuting mode, indicating a strong mode choice inertia. Furthermore, he showed that the opposite phenomenon is not true, i.e., car commuters enjoying a shorter commuting time will not likely shift to a slower mode.

Several elements can explain the modal shift toward private vehicles after workplace relocation. Firstly, as mentioned previously, employees try to keep travel times below a certain threshold. Secondly, suburban locations often offer free or cheaper parking and good road accessibility while, on the other hand, the public transport system might be less efficient (because of higher interchange probability).

According to Aarhus (2000), the sustainability of a working place, which to some extent is related to its accessibility, can be assessed by analyzing how workers adapt to this new working environment. However, assessing a workplace modal shift by verifying whether or not the employees change their commuting mode might be a shortsighted approach. Other decisions, in the short and long term, may be influenced by this exogenous event. Workers often select their residence according to several criteria and among them is the home-to-work distance. After workplace relocation, it is assumed that people who face workplace relocation and those who don't ("new comers") will not eventually live in the same area and thus will not share similar commuting behaviors. Modal shifts toward private or public transportation (PT) modes are important statistics, but the modal split before and after the relocation events should also be put into perspective. When assessing accessibility variation due to workplace relocation, not only does the difference in distance matter, but also the difference in accessibility. If previous workplace accessibility was poor, a slight improvement could be seen as a positive outcome, even though the accessibility of the new location may not be optimal. The opposite is also true, i.e., a slight loss in accessibility from a situation that was ideal can still be seen as satisfactory.

The loss of attractiveness related to a lower level of accessibility can be seen as a negative factor penalizing private companies or public institutions that relocate their infrastructure from the city center into peripheral areas. Some individuals choose employment positions to a large extent based on their working environment and the proximity to other points of interest. A change of this environment could not only lead some employees leaving, but also increasing the difficulty of attracting new workers (Bell, 1991).

When faced with workplace relocation, individuals may adapt in various ways. In 1991, Bell pointed to several short-, mid- and long-term adaptation strategies ranging from shifting toward a faster commuting mode to compensate for a longer home-to-work distance, to quitting the job, or moving home. Decisions that are likely to be significantly affected are daily activities usually linked with home and work activities, for instance daily shopping, or eating out at lunch, etc. These decisions may, in turn, partly be the reason for modal shifts. This conscious modification of activity patterns and thus the activity space of the individual facing workplace decentralization is one example of mid-term adaptation. Bell (1991) observed, for instance, that individuals facing workplace relocation performed, on average, fewer activities (including non-work activities) after the move to the new working environment (dropping from 2.2 to 2 activities per day per person).

As indicated by mobility biography studies such as Rau and Manton (2016) and Schoenduwe et al. (2015), some life events lead to a modification of individuals' travel behavior. Because workplace relocation will impact all employees' commuting trips, private companies or public institutions might try to benefit from this event by changing traveling habits and in particular by encouraging use of public transport and soft modes (bike and walk). Bamberg (2006) showed that a temporary intervention after 
an important life event (residential relocation) had an important positive effect on an individual's longterm travel behavior.

This paper contributes to the research direction indicated by Bell (1991) who has, using two crosssectional travel surveys, analyzed the impact of workplace suburbanization of a private company on the activity pattern of the workforce. While his study proposed an analysis of the modification of the activity type and timing (including non-work activities) due to workplace suburbanization, it did not cover an important element of the activity pattern modification — its spatial dimension.

In this paper, we aim to provide this complementary view. The research question addressed is the following: how do workers choose the location of the activities that were linked to the previous workplace location? More specifically, did the individuals modify all locations for their activities or did some activity locations remain unchanged? Being able to quantify the modification of the employees' activity space due to the relocation of their working place is the central objective of this paper, and hence represents the main contribution of our study.

\section{Context and data collection}

\subsection{Luxembourg, the heart of a cross-border region}

At the heart of Europe, with an area of $2,586 \mathrm{~km}^{2}$, the Grand-Duchy of Luxembourg is a small country facing big mobility challenges. Every day, in addition to the commuting trips of its 563,000 residents, the country is also welcomes 170,000 cross-border workers, which represent $43 \%$ of the total work force (STATEC, 2016). These cross-border workers coming from Belgium, France and Germany generate an increased pressure on the transport infrastructure of the country. While $76 \%$ of the workers living in Luxembourg commute by car, the share reaches $89 \%$ for cross-border workers (Carpentier \& Gerber, 2009). Public transport use is relatively low despite the high service quality in terms of both frequency and coverage (Klein, 2010). As mentioned by Epstein (2010), high car usage may be explained partly by the dense motorway network and the positive image of the car. Regarding commuting mode choice, the important difference between resident and cross-borders workers is mainly related to home-to-work distance. For residents, the median commuting distance is $12 \mathrm{~km}$, while it reaches $40 \mathrm{~km}$ for cross border commuters (Carpentier \& Gerber, 2009). Despite being a car-dependent country, ambitious modal split targets have been adopted. According to directives by the Ministry of Sustainable Development and Infrastructure, by $202025 \%$ of all trips should be performed using non-motorized modes of transportation (walking and bike), while of the remaining 75\%, 25\% should be done by public transport (PT). In brief, $25 \%$ of trips should be done by soft modes, $19 \%$ of trips by public transport and, finally, $56 \%$ by car. According to the private company Tom-Tom (TomTom Traffic Index, 2015), a 30-minute daily commuting trip will result in 87 hours of delay over the year.

The high congestion levels experienced in Luxembourg are also related to the monocentric development of the country. Out of the 380,000 jobs available in the country, approximately one in two is located in Luxembourg City (Walther \& Dautel, 2010). In order to decrease the pressure (in terms of commuting flow, residential prices, etc.) on Luxembourg City, and to reach a more balanced polycentric development across the country, a decentralized concentration land-use policy has been implemented. Chilla and Schultz (2014) describe this policy as the "concentration of urban and infrastructure development in selected cities and communities of different levels of centralization." The development of Belval, a new town located in the south-west part of the country, is seen as a powerful tool toward achieving more polycentric development. This site, a former industrial area requalified and renovated, hosts most of the university infrastructure, many national research centers, company headquarters, a hotel, theatres, music hall, a train station and various types of accommodation. This new center of activity is also ex- 
pected to increase the attractiveness of the surrounding cities, thus favoring the expansion of the whole South-West region in the long run.

\subsection{The University of Luxembourg}

Founded in 2003, the University of Luxembourg welcomes 6,500 students and 1,500 staff members daily. Until August 2015, the majority of the University activities were located on three different campuses, in Luxembourg City (namely Kirchberg and Limpertsberg campuses) and a few kilometers away from the city center (Walferdange campus). In September 2015, the faculty hosted in Walferdange was the first to relocate. The buildings of this old campus are no longer in use by the University.

Since its creation, the university has consistently seen a rise in the number of its employees and students, but had to slow its expansion due to the limited available infrastructure. To solve this issue, and to foster polycentric land-use development, the national government chose to relocate the university to Belval. The move of most of the university facilities was guided by a lack of space due to a constantly growing population (both students and staff members) and the wish to concentrate all activities on one site.

A previous study, involving earlier travel survey data showed that most of the staff members would be negatively impacted in terms of commuting traveling, the most impacted staff members being German workers, while only a few would benefit from shorter commuting distances (Sprumont, Viti, Caruso, \& König, 2014). In general, this workplace relocation would increase the commuting of university staff members by, on average, $18 \%$ (from 28.7 to $33.8 \mathrm{~km}$ ). On the other hand, this workplace relocation is seen as a unique opportunity to foster a sustainable vision of mobility, with carrot-stick measures being implemented to encourage modal shifts toward public transport and soft modes. Moves include a parking fee, a university car-sharing system, an online carpooling platform, and an inter-campus shuttle, all with the aim of mitigating the expected car use increase for commuting trips.

\subsection{The data collection phases}

In September 2015, the faculty located in Walferdange was the first to relocate, and the buildings of the old campus were left by the university to other institutions. This was seen as an opportunity to collect a relatively unique dataset that could help gain insight into the impact of workplace relocation to people's daily activity-travel patterns. To this end, in 2015, prior to the moving operations, a communication campaign was implemented to attract staff members willing to participate in our study. This involved collecting a multi-day travel diary, complemented with a preliminary questionnaire aimed at collecting socio-demographic data and commuting trip related attributes. Because of the case study and the specificities of the respondents, (e.g., highly educated university staff members) data and results obtained can certainly not be generalized to any other case study, but the collected data certainly provides valuable insight into the dynamics arising from an important life event such as workplace relocation. Tests using a larger sample, as well as on different working environments would be needed to properly validate our methodology, but this is left as an option for future research.

For two weeks, respondents provided information regarding their activities (type, location, duration) and the associated trip (travel time, travel mode) using a dedicated web-based survey. This activitybased survey was developed using the tool Qualtrics and was designed in such way to collect information every time participants left a building.

Between May and June 2015, respondents had to provide two weeks of information. An overview of the questionnaire structure is provided in the appendices.

At the time of data collection, the total number of staff members in Campus Walferdange was ap- 
proximately 600 individuals. Our target was to reach around $8-10 \%$ of the population in our sample. This was seen as reasonable given that a multi-day survey requires significant effort and a reasonable financial incentive (100 EUR per respondent) in the form of a gift voucher was offered.

One year after the first data collection phase, the same individuals were re-contacted and invited to repeat the survey. We opted for doubling the financial incentive for the second phase, as the two-weeks diary is an extremely tedious work for the respondents and we feared a significant number of dropouts after the first phase, which would have reduced the quality of the data. Instead, the response rate remained high. In total eight people could not participate in the second round of data collection for various reasons. Two respondents were not available during the specific period, one respondent was on maternity leave and five respondents were no longer working at the university at that time.

In total, 43 individuals took part in both the 2015 and 2016 data collection phases. In 2016, an additional questionnaire regarding the modification of other elements in their life was also submitted (see Appendix C) to the respondents before providing them with the last monetary incentive. This final set of questions informed us about the possible mid and long-term adaptation strategies (see Bell, 1991, p. 151, for a detailed description of the adaptation strategies). In total, 27 of the 43 respondents did not report any significant event such as buying a car, home relocation, having a baby, etc., therefore workplace relocation was for them the main event affecting their commuting traveling experiences and their activity-travel decisions. On the other hand, among the respondents, eight people had relocated their home address.

Clearly, the size of the dataset collected cannot guarantee generality of the observed changes in both short- and long-term decisions, so the results presented in this section and later in the analysis of the mobility patterns have to be treated as explorative. Moreover, we cannot fully ensure that all long-term decisions and travel choices of the respondents have converged toward a new set of habitual routines within the chosen time interval. However, we argue that the exploratory analysis presented in this paper provides a strong methodological contribution in the way activity-travel patterns are compared and clustered, as well as it points in several directions for further research, and gives clear indications of the importance of performing similar types of data collection campaigns in the future.

\section{Descriptive analysis}

Because the objective of this study is to assess the effect of workplace relocation on activity-travel behavior, only data encoded during weekdays where a work activity was registered were taken into account. Weekend days, bank holidays or week days without any work activity described were simply not considered. For the 2015 data set, out of the 598 days described by the 43 respondents, 370 (62\%) were retained for analysis while for the 2016 data set, out of the 615 days of information, 361 (59\%) were retained for the following analysis.

All the respondents have one characteristic (at least) in common, i.e., between 2015 and 2016 their workplace has been shifted from Walferdange to Belval. While the comparison of both 2015 and 2016 travel diaries is assumed to be an adequate tool to analyze short-term adaptation (commuting mode change, modification of the activity pattern) some respondents changed some elements of their life that can be considered long-term adaptation to workplace relocation, such as changing their residence or buying a car. In total, eight individuals (18.6\%) relocated their house but not necessarily because of the workplace relocation. Long-term decisions do not always move toward improving the commuting travelling experience, and the individuals do not necessarily aim to minimize the commuting times. In general, respondents may try to trade off this cost with other benefits that could be obtained from other long-term decisions. Two respondents moved from Luxembourg to Trier (Germany) because of cheaper rental prices across the border. Another respondent was living near Belval before the relocation but after- 
wards this person decided to move because, as stated by the respondent, he/she did not want to live and work in the same place. This kind of behavioral adaptation is in line with the theory of Redmond and Mokhtarian (2001) stating that travelling might, to some extent, have a positive utility. The behavior of this individual can be synthesized by: the work place should be close, but not too close to home.

On average, the respondents of our survey had a median number of activities per day of 4.1 in 2015 and 4.2 in 2016. Large differences can be observed between individuals, for example, one individual conducted 2.5 activities per working day which is very close to a daily Home-Work-Home and another one conducted on average 7 activities per working day.

\subsection{Impact on the commuting distance}

In 2015, before the workplace relocation, the average home-to-work distance for the 43 respondents reached $30.2 \mathrm{~km}$ and $14 \mathrm{had}$ a commuting trip shorter than $10 \mathrm{~km}$. Of course, the commuting distance was different for Luxembourgish residents than for cross-border workers. Indeed, in 2015, the crossborder workers had on average a commuting trip of $60.4 \mathrm{~km}$ while Luxembourgish residents had an average commuting distance of $15.5 \mathrm{~km}$.

In 2016, after the move of the Walferdange campus to Belval, the average commuting distance reached $38.5 \mathrm{~km}$. Only 5 survey respondents now have a home-to-work trip of less than $10 \mathrm{~km}$. From the 14 staff members who, in 2015, had a short commute, 12 (the 2 remaining have relocated their house) now have a commuting trip longer than $20 \mathrm{~km}$. In 2016, the cross-border workers had, on average, a commuting distance of $67 \mathrm{~km}$, while for residents the trip on average reached $21 \mathrm{~km}$.

Concerning the commuting distance, even if the sample is not large enough to make a solid generalization of the observations, the home-to-work trips have, on average, significantly and systematically increased in length. Intuitively, this increase of the commuting distance is related to staff members' previous residential choices. Before the relocation, many respondents were living relatively close to their work place, but the move of the university infrastructure had a big impact on them. In addition, there are too few staff members living in the surroundings of the new campus to compensate for the general distance increase

\subsection{Impact on the commuting mode choice}

Confirming what Vale (2013) indicated on travel mode choice inertia, $80 \%$ of the respondents did not change their main travel mode despite the workplace relocation. In $2015,56 \%$ of the sample was commuting by car, $42 \%$ by public transport and $2 \%$ by soft modes. After the relocation, $60 \%$ of the individuals are doing their home-to-work trip by car, 35\% using public transport and 5\% by walking or bike.

Compared to Bell (1991), where the modal shift toward the car was important, the respondents did not significantly change their habits. This relatively small modal split variation after the workplace relocation, despite a general distance increase, is probably related to the parking costs imposed on the Belval site. As pointed out by Aarhus (2000) the availability of free parking is a strong car use determinant for the home-to-work trip. While the University of Luxembourg was providing free parking on the old campus site (Walferdange) this is no longer the case on the new campus (Belval). 
Table 1: Comparative table between 2015 and 2016 situations

\begin{tabular}{|c|c|c|c|c|c|c|c|c|}
\hline \multirow{3}{*}{ Commuting time (in minutes) } & \multicolumn{4}{|c|}{2015} & \multicolumn{4}{|c|}{2016} \\
\hline & Min & Max & Average & STDEV & Min & Max & Average & STDEV \\
\hline & 11.9 & 118.0 & 47.3 & 23.3 & 10.0 & 122.1 & 52.4 & 27.7 \\
\hline $\begin{array}{l}\text { Commuting distance (in } \mathrm{km} \text { ) } \\
\text { (on road the network) }\end{array}$ & 2.7 & 118.0 & 30.2 & 27.2 & 0.7 & 110.7 & 38.5 & 27.6 \\
\hline $\begin{array}{c}\text { Kilometers travelled per } \\
\text { considered day per respondent }\end{array}$ & 13.9 & 249.9 & 83.6 & 56.2 & 8.8 & 223.7 & 91.9 & 52.4 \\
\hline $\begin{array}{l}\text { Kilometers travelled by car per } \\
\text { considered day per respondent }\end{array}$ & 0.0 & 249.4 & 54.0 & 51.2 & 0.0 & 223.5 & 64.1 & 56.5 \\
\hline $\begin{array}{l}\text { Kilometers travelled by PT per } \\
\text { considered day per respondent }\end{array}$ & 0.0 & 121.5 & 23.1 & 33.8 & 0.0 & 149.4 & 24.6 & 40.4 \\
\hline $\begin{array}{l}\text { Kilometers travelled by Soft Modes } \\
\text { per considered day per respondent }\end{array}$ & 0.0 & 5.8 & 1.2 & 1.5 & 0.0 & 9.1 & 1.2 & 1.5 \\
\hline Commuting modal split ${ }^{1}$ & \multicolumn{4}{|c|}{ Car: $56 \%$, PT: $42 \%$, Soft: $2 \%$} & \multicolumn{4}{|c|}{ Car: 60\%, PT: $35 \%$, Soft: $5 \%$} \\
\hline $\begin{array}{l}\text { Activity per considered day } \\
\text { per respondent }\end{array}$ & 2.5 & 7.0 & 4.2 & 1.1 & 2.4 & 9.4 & 4.3 & 1.4 \\
\hline $\begin{array}{l}\text { Non-working activities per } \\
\text { considered day per respondent }\end{array}$ & 1.4 & 5.8 & 3.0 & 1.0 & 1.3 & 8.3 & 3.1 & 1.3 \\
\hline $\begin{array}{c}\text { Shopping activities per } \\
\text { considered day per respondent }\end{array}$ & 0.0 & 0.9 & 0.3 & 0.2 & 0.0 & 1.7 & 0.7 & 0.4 \\
\hline $\begin{array}{l}\text { "Drop off / pick up s.o" activities per } \\
\text { considered day per respondent }\end{array}$ & 0.0 & 2.9 & 0.4 & 0.6 & 0.0 & 6.4 & 0.8 & 1.3 \\
\hline
\end{tabular}

${ }^{1}$ The commuting modal split is here define as the mode used on the longest distance and the most regularly by each respondent.

\subsection{Impact on commuting time}

While the commuting distance increased to a rather considerable extent, commuting time of the respondents shifted from 47 minutes to 52 minutes. This increase of 5 minutes is rather small if compared to a distance increase of $8 \mathrm{~km}$. The second data collection phase was organized 11 months after the moving operations; thus, our assumption is that respondents should have implemented the short-term adaptations (commuting mode choice, activity location). However, it is not possible to know if all the respondents have finished their exploration phase regarding, for instance, commuting mode choice, route choice or activity location. On the other hand, other respondents already adopted mid- and longterm strategies to cope with the relocation of their workplace to Belval. A third data collection phase would allow us to gain insights about the length of the exploration phase, but this was unfortunately not planned before the study took place. 


\section{$5 \quad$ Methodology}

With the objective of finding a synthetic measure of the effect of workplace relocation on the activity patterns of university staff members, in this study, we adopt the Standard Deviational Ellipses approach. Our goal is to show that such an event produces a systematic change in the spatial distribution of activities. To the best of our knowledge this analysis has never been done in past research.

The quantification of spatial event dispersions using Standard Deviational Ellipses (SDE) is a wellestablished technique dating from the beginning of the 20th century (Lefever, 1926). Since then, SDE technique has evolved (Yuill, 1971) and gained in robustness (see, for instance, Gong, 2002, who discusses whether a standard deviation curve should be used instead of the classical SDE) and popularity (Buliung \& Kanaroglou, 2006). The characterization of individuals' activity spaces using Standard Deviational Ellipses (SDE) has already been successfully implemented in activity-travel behavior analysis (Schönfelder \& Axhausen, 2003; Drevon, Gerber, Klein, \& Enaux, 2013; Perchoux et al., 2014).

Our dataset is characterized by a relatively low number of individuals (43 in total) as well as a relatively large number of days/activities described per respondents. In this context, SDE is seen as an interesting tool to assess a modification of the activity space of the individuals after their workplace relocation. This is because it translates complex spatial and temporal activity patterns into simple and interpretable parameters. Of course, other methods such as the space-time prism (Kwan, 1998) or the convex hull surface (Perchoux et al., 2014) might also provide valuable information on the activity space or the activity pattern. However, Standard Deviational Ellipse, in addition to its efficiency in characterizing the activity space, seems to be the most appropriate approach for comparing two different activity spaces and deriving a set of indicators such as length, rotation or area variation.

The 86 ellipses ( 1 per respondent for all reported working days before and after the relocation) have been obtained using ArcGIS software and a dedicated tool to perform SDE.

The two main parameters (length, width) of the Standard Deviational Ellipse for one activity space are defined as:

$$
\begin{aligned}
& S D E_{x}=\sqrt{\frac{\sum_{i=1}^{n}\left(x_{i}-\bar{X}\right)^{2}}{n}} \\
& S D E_{y}=\sqrt{\frac{\sum_{i=1}^{n}\left(y_{i}-\bar{Y}\right)^{2}}{n}}
\end{aligned}
$$

Where $x_{i}$ and $y_{i}$ are the coordinates of location I and where $\mathrm{X}^{-}$and $\mathrm{Y}^{-}$are the mean center for all the activity locations and $\mathrm{n}$ equals the total number of activities considered for the ellipse generation (Yuill, 1971). More information on the weighting procedure and on the angle of rotation computation can be found in Mitchell (2005).

Figure 1 provides an illustrative example of how SDE works using different weighting parameters. The West location A is the individual's home and is, in this example, visited for 5 days and for a total of 76 hours. The east location D is the individual's workplace and is visited also 5 times, but for less time, i.e., a total of 40 hours. The north and south locations (B and C, respectively) are both leisure activities, the former being a restaurant visited once for a total of 1 hour and the latter a sport infrastructure that has been visited 4 times (for a total of 4 hours). Sub-Figure 1b, shows a simple non-weighted SDE while the sub-Figure $1 \mathrm{c}$ and $1 \mathrm{~d}$ show respectively time (activity time) and visits weighted SDE.

We argue that a non-weighted SDE would not be not appropriate for our study, because all the visited places would appear to bear the same importance level, even if they have only been visited once for 5 minutes or 10 times for a total of 80 hours. The time-weighted approach gives importance to 
places that are visited for long durations, and hence provides an unbalanced result between short activities (lunch in a restaurant for instance) and long duration activities (12h spent at home before going to work again). Thus, the frequency-weighted SDE has been selected due to the fact that the weight difference between anchor locations, and locations visited occasionally for a limited period of time, exists but remains reasonable.

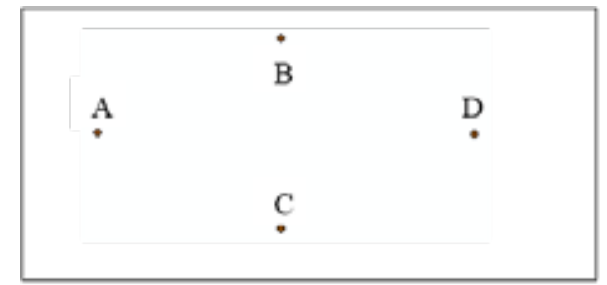

a) Four activity locations

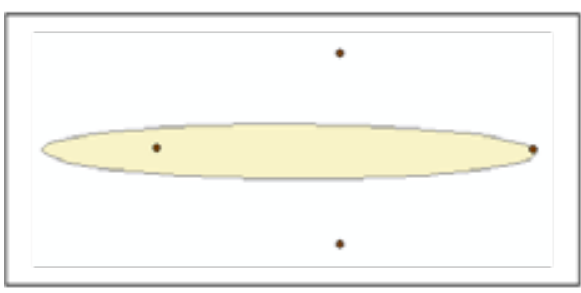

c) Four activity locations with time weighted SDE

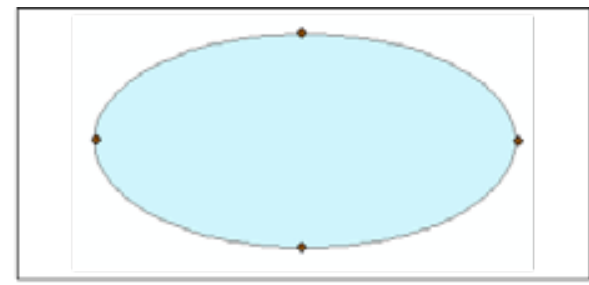

b) Four activity locations with non-weighted SDE

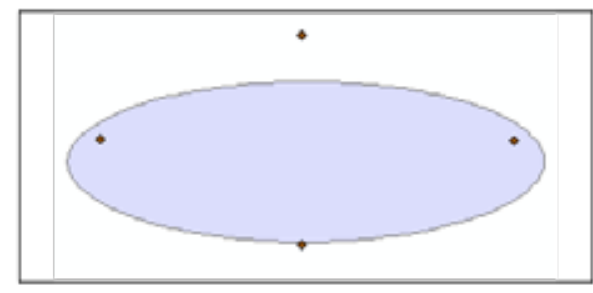

d) Four activity locations with visits weighted SDE

Location A: Living place: 5 visits -4560 minutes

Location C: Sport Club: 4 visits -240 minutes

Location D: Workplace: 5 visits -2400 minutes

Location B: Restaurant: 1 visit -60 minutes

Figure 1: Standard Deviational Ellipses with different weights

\section{Results of the SDE on the case study}

Because activity places that are located far away from the mean center have an important effect on the SDE feature (rotation, length and width), some remote and non-habitual activity locations were not considered as it was assumed that they were exceptional events not recurring every week and hence they would be a biased information in a two-weeks diary. The specificity of the sample population (mostly academic personnel) is partly responsible for special events observed, such as conferences abroad. Some individuals also began trips to visit family members or friends in remote places on Friday evening. Out of a total of 581 different activity locations, 23 places were not retained for the construction of the 86 Standard Deviational Ellipses.

Due to the significant distance $(20 \mathrm{~km})$ between the old and the new workplace, we expected that the relocation would have a non-negligible impact on the activity space, represented by the Standard Deviational Ellipses. Concerning the Ellipses' area variation between 2015 and 2016, for instance, the median increase reached 56\%. In total, 25 respondents (out of 43) experienced an increase of their activity space. Concerning the length of the SDE, the median increase is $50 \%$. Of course, this increase of the ellipses' length is associated with the commuting distance increase mentioned previously which is concomitantly affecting the ellipses' area.

The area of the activity space varies significantly depending on the individuals' characteristics. For instance, in 2015, one respondent conducted 38 activities during 10 working days within an activity space of $6 \mathrm{~km}^{2}$. At the other side of the spectrum, one respondent had, in 2015, an activity space of $2,729 \mathrm{~km}^{2}$. 


\subsection{Clustering analysis}

The ellipses were generated on the individual's activity locations both for 2015 (before the relocation) and 2016 (after the relocation). In order to verify if some individuals had an activity pattern variation which could be considered as abnormal compared to the total sampling, a basic multivariate outlier analysis was performed. The Mahalanobis distance computed for each individual leads us to exclude one individual from the clustering analysis (appendix B includes the computed Mahalanobis distances and the $\mathrm{Chi}^{2}$ test). After verification, the length of the activity space (represented by the SDE) of this person increased by $1400 \%$ and its area increased by $4700 \%$. In this case, a professional collaboration with an institution from a neighboring country is the cause of such important variation in the activity space.

Next, a K-means clustering approach was performed on a derived dataset consisting of the variation of the ellipses between 2015 and 2016. More specifically, the six variables considered for the cluster analysis are:

1) ellipses width change

2) ellipses rotation change

3) ellipses length change

4) ellipses area change

5) overlapping between 2015 and 2016 ellipses, and

6) variation of the distance between respondents' home and the center of the ellipse after the workplace relocation.

The results of the K-means clustering approach with three clusters are presented in table 2. Cluster 1 gathered individuals who had the smallest overlap (17\%) between their 2015 and 2016 activity spaces. Respondents belonging to this cluster also faced a substantial rotation of their activity spaces (106 degrees on average). Obviously, members of cluster 1 faced an important modification of their activity space after the relocation. It turns out that from the five people of this cluster, 3 decided to relocate their residence. Interestingly, these three individuals were also living in Luxembourg before the relocation, meaning that their residence relocation was within the national borders. All the members of this group live in Luxembourg

Table 2: Results of K-Mean cluster analysis

\begin{tabular}{|c|c|c|c|c|}
\hline Cluster & $\mathbf{1}$ & $\mathbf{2}$ & $\mathbf{3}$ & Total \\
\hline Size & $5(12 \%)$ & $11(26 \%)$ & $26(62 \%)$ & $43(100 \%)$ \\
\hline Average width change (in \%) & $13.3 \%$ & $79.2 \%$ & $18.9 \%$ & $38.3 \%$ \\
\hline Average rotation change (in degrees) & 105.67 & 48.70 & 12.65 & 35.1 \\
\hline Average length change (in \%) & $67.0 \%$ & $79.6 \%$ & $42.7 \%$ & $86.9 \%$ \\
\hline Average area change (in \%) & $139.3 \%$ & $199.8 \%$ & $57.9 \%$ & $212.4 \%$ \\
\hline Average overlapping (in\%) & $13.9 \%$ & $34.4 \%$ & $32.7 \%$ & $32.5 \%$ \\
\hline $\begin{array}{c}\text { Average variation of the Home - } \\
\text { Ellipse center distance (in\%) }\end{array}$ & $17.0 \%$ & $80.5 \%$ & $46.2 \%$ & $55.9 \%$ \\
\hline
\end{tabular}

Cluster 2 is composed of individuals who faced a major increase of their activity space after workplace relocation. Indeed, on average, the width of their SDE increased by $79 \%$, the length increased by $80 \%$ and consequently, the area increased by 200\%. In 2015, 10 out these 11 respondents were also living in Luxembourg. As introduced previously, a major increase of the activity space may be due to the fact that these people are still in exploration phase or trying to combine the activity location they know (because 
of habits, emotional relation, etc.) as well as conducting activities around their new workplace. Such behavior could lead individuals to have a bigger activity space.

The third cluster gathers respondents that faced the smallest rotation, length and area variations. Half of the respondents within this cluster are university staff members living outside Luxembourg. Out of the 13 cross-border workers (in 2015), 12 (92.3\%) are in this cluster. Because of a small rotation and a rather large overlap (32.7\%) between 2015 and 2016 activity spaces, respondents from this cluster probably required less effort to cope with the workplace relocation, at least concerning their activitytravel behavior.

Table 3 presents the socio-demographic characteristics among the 3 different clusters. For instance, as discussed, the allocation of cross-border workers among the clusters is uneven. Considering the low number of respondents, these results are provided as an indication and cannot be proven in general.

Table 3: Socio-demographic characteristic among clusters

\begin{tabular}{|c|c|c|c|c|c|c|c|}
\hline & \multicolumn{2}{|r|}{ Cluster1 } & \multicolumn{2}{|r|}{ Cluster 2} & \multicolumn{2}{|r|}{ Cluster 3} & \multirow{2}{*}{ Total } \\
\hline & \# & $\%$ in the cluster & \# & $\%$ in the cluster & \# & $\%$ in the cluster & \\
\hline Cross-border & 0 & $0 \%$ & 1 & $9 \%$ & 13 & $50 \%$ & 14 \\
\hline Female & 4 & $80 \%$ & 10 & $91 \%$ & 17 & $65 \%$ & 31 \\
\hline Male & 1 & $20 \%$ & 1 & $9 \%$ & 9 & $35 \%$ & 11 \\
\hline PhD students & 2 & $40 \%$ & 5 & $45 \%$ & 6 & $23 \%$ & 13 \\
\hline Prof, PostDoc and Researchers & 3 & $60 \%$ & 4 & $36 \%$ & 11 & $42 \%$ & 18 \\
\hline Admin or technical positions & 0 & $0 \%$ & 2 & $18 \%$ & 9 & $35 \%$ & 11 \\
\hline Living with children & 1 & $20 \%$ & 3 & $27 \%$ & 8 & $31 \%$ & 12 \\
\hline Average Age & & 34.4 years & & 34.4 years & & 35.3 years & 34.9 years \\
\hline
\end{tabular}

Figure 2 provides a visualization of a representative respondent from each of the three clusters. These clusters representatives have been selected because they have the shortest distance to the center of the cluster. Appendix B contains details for individually analyzing the variation between the 2015 and 2016 SDEs, the cluster allocation and the distance to the center of the cluster.

The workplace relocation has a different impact on the activity space represented by the SDE. The effect depends widely on the position of the individual's home compared to the old and the new workplace locations. An interesting element is that, after the workplace relocation, very few respondents still had activities within a buffer of $5 \mathrm{~km}$ around the previous campus. Only four respondents, representing less than $10 \%$ of the sample population, had activities in the direct vicinity of their former working place in 2016. This indicates that, after a year, people adapted their daily activity pattern, keeping the activity place close to their home and replacing the location of the activities close to the previous workplace.

A simple correlation analysis between the 2016 ellipses length and the 2016 commuting distance revealed a correlation of $89 \%$. Intuitively, this indicates that the commuting distance strongly affects the length of the activity space. 
Table 4: Mobility behavior among clusters

\begin{tabular}{|c|c|c|c|c|}
\hline Cluster & $\mathbf{1}$ & $\mathbf{2}$ & $\mathbf{3}$ & Total \\
\hline Size & $5(12 \%)$ & $11(26 \%)$ & $26(62 \%)$ & $43(100 \%)$ \\
\hline $\begin{array}{c}\text { Commuting distance in 2015 \& 2016 } \\
\text { respondents in 2015 \& 2016 }\end{array}$ & $10,0-22,6$ & $15,3-26,9$ & $41,3-46,1$ & $30,7-38,5$ \\
\hline $\begin{array}{c}\text { Average total kilometers travelled by car per day per } \\
\text { respondents in 2015 \& 2016 }\end{array}$ & $43,0-48,9$ & $53,0-63,5$ & $\begin{array}{l}106,5- \\
111,45\end{array}$ & $85,0-91,9$ \\
\hline $\begin{array}{c}\text { Average total kilometers travelled by PT per day per } \\
\text { respondents in 2015 \& 2016 }\end{array}$ & $9,4-11,3$ & $32,1-21,7$ & $22,4-28,3$ & $23,4-24,6$ \\
\hline $\begin{array}{c}\text { Average total kilometers travelled by soft modes per } \\
\text { day per respondents in 2015 \& 2016 }\end{array}$ & $0,6-1,2$ & $1,9-1,2$ & $1,0-1,3$ & $1,2-1,2$ \\
\hline
\end{tabular}

The average modification of the commuting distance (on the road network) was extracted for each of the three clusters. While it has already been mentioned that respondents from cluster 1 faced a significant change to their activity space, they also faced an increase of $126 \%$ of their Home-to-Work distance (from $10 \mathrm{~km}$ to $22.6 \mathrm{~km}$ ). The second cluster composed mainly of people living in Luxembourg who faced an enlargement of their activity space and had to cope with an increase of $76 \%$ to their commuting distance (from $15.3 \mathrm{~km}$ to $26.9 \mathrm{~km}$ ). Rather logically, respondents from cluster 3, of whom $50 \%$ were cross border workers, had a very long commuting trip $(41.3 \mathrm{~km})$ in 2015 , but only faced a minor increase of $13 \%$ in 2016 and now commute, on average, $46.8 \mathrm{~km}$, for a one-way trip. 


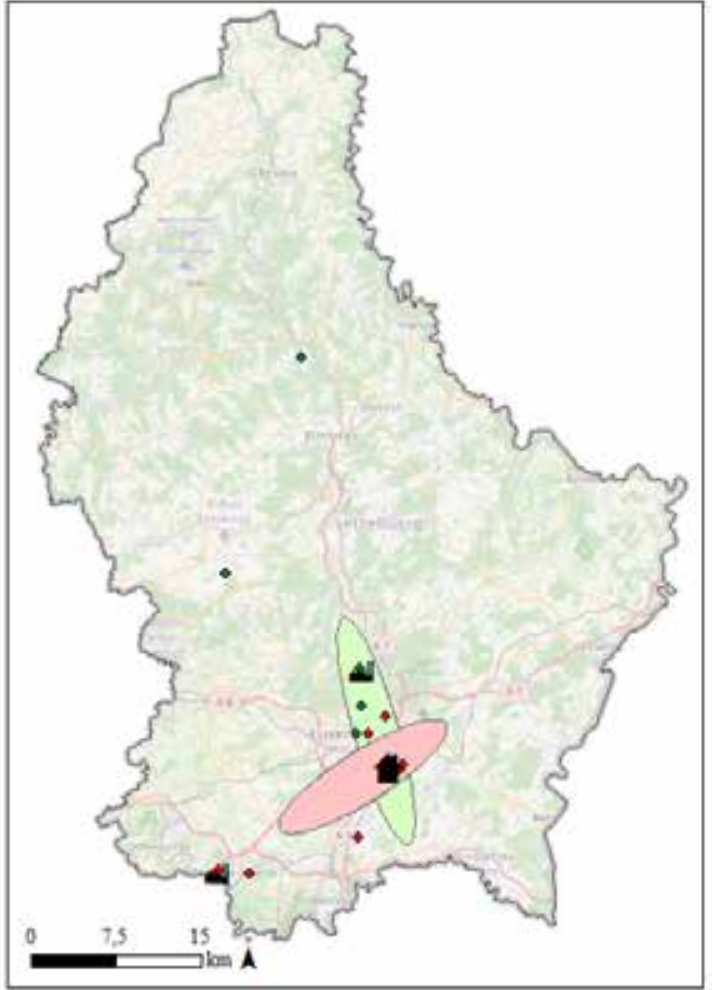

a) Representative of cluster 1

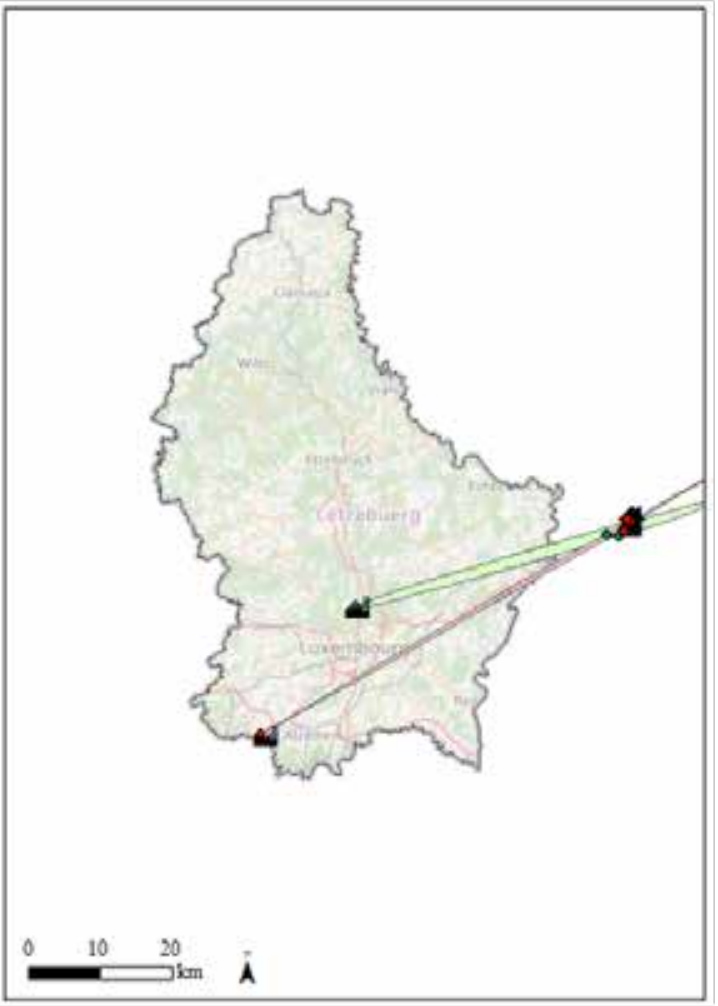

c) Representative of cluster 3

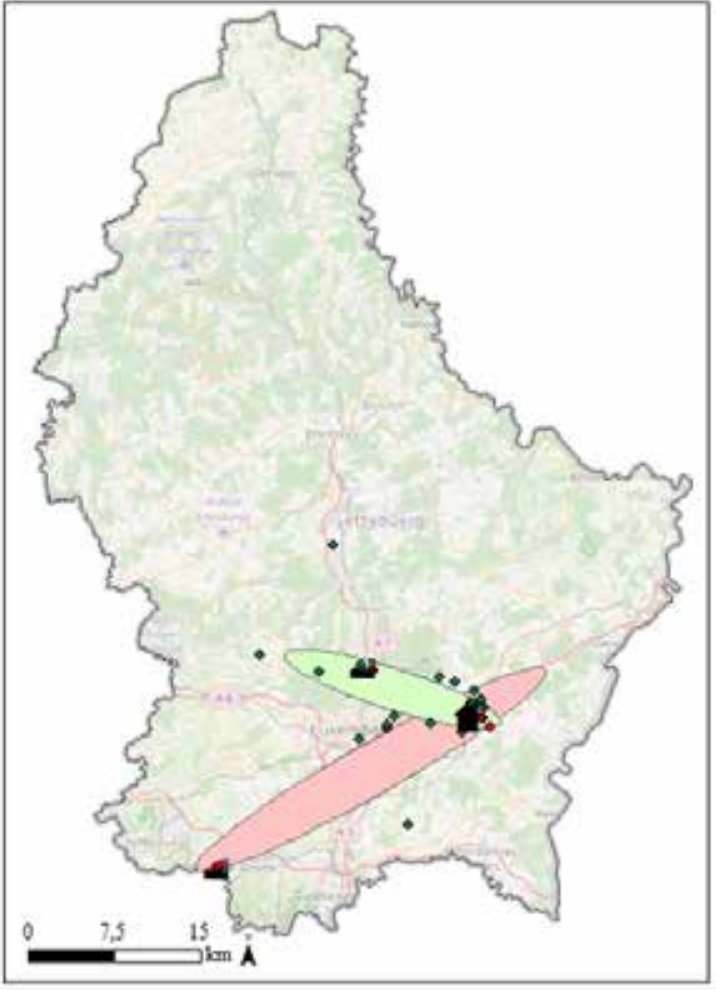

b) Representative of cluster 2

\section{Legend}

m.ll Walferdange (North, Old campus)

wh Belval (South, New campus)

A Respondent's Iiving place

- 2016 Activity Locations

- 2015 Activity Locations 2016 Activity Space 2015 Activity Space National Border

Realization: Sprumont Francois MobiLab, University of Luxembourg

Figure 2: Clusters Representative 


\section{$7 \quad$ Discussion and conclusions}

Similar to findings available in existing scientific literature, and despite using a small sample, it has been confirmed that an instance of workplace decentralization leads to longer home-to-work commuting trips. This result is in conflict with the co-location hypothesis reported in the literature (Gordon \& Richardson, 1997).

Due to the significant distance between the new and the old workplace $(20 \mathrm{~km})$, the activity spaces of the respondents were greatly modified. The employment of Standard Deviational Ellipses combined with a cluster analysis allowed a quantification of the modification of the activity space and the distinction between three types of profile.

After the workplace was relocated, very few individuals continued to conduct activities in the area of the old campus. Of course, such an impact might have some strongly negative impacts on the frequency of visits to services located close to the previous working space. Transport demand might also change depending on the size of the institution being relocated.

The analysis developed in this paper showed that, during working days, the place of residence and the working place were important anchor points shaping the entire activity space. The analysis carried out can be reproduced for different case studies, and, to some extent, employed in order to forecast the effect of another workplace relocation event on the employees' activity space.

On the land-use management side, the development of Belval, which is in line with the so-called decentralized concentration concept, turned out to be an effective way to decrease the pressure on the transport infrastructure of the capital. Indeed, only four individuals still have activities in the area of the old campus. While no quantitative analysis has been carried out specifically on this topic, it is assumed that the effectiveness of such a policy strongly depends on the distance between the new and the old workplace. While in this case, with a distance of $20 \mathrm{~km}$, the vast majority of individuals changed totally their activity space, a relocation of $5 \mathrm{~km}$ would most likely have led people to keep some activity locations unchanged out of habit. If the workplace decentralization's main objective was to reduce the transport demand around the old place of work, the distance to the new place of work is an important element which must not be ignored.

Analyzing the effect of a workplace on employees' travel behavior and activity patterns is a complex task, where the research objective has to be thoroughly designed. For instance, concerning the data collection, if the objective is to assess the accessibility or sustainability of the new place of work, it is suggested that only the commuting behavior of "new comers" is analyzed. If the goal is to check long-term adaptation (moving to a new home, buying a car) to workplace relocation then it is suggested that the second data collection is carried out a couple of years after the move. Finally, if the goal is to understand short-term adaptation (mode change, activity location modification) to workplace relocation, such as in this study, collecting data before and up to one year after relocation is the recommended strategy.

This scientific study can be considered explorative, and future developments would be needed to allow a generalization of the results. Bigger and more frequent data collection should be organized. Due to the difficulty in collecting data regarding the effect of workplace relocation on activity-travel behavior, this topic remains largely unexplored. Nevertheless, work-place relocation occurs frequently, and the effect on employees needs to be investigated further. The use of ICT and other transformative technologies should also be studied in this context because these technologies might mitigate the potential negative impact of workplace relocation on individuals' time budgets. 


\section{Acknowledgements}

This research has been funded by the Luxemburgish FNR ("Fonds National de la Recherche") through an AFR grant for the STABLE project (7951609), and by the EU Marie-Curie funded project InCoMMune (618234). The authors are grateful to Dr. Marco Rinaldi and Kerry Schiel for valuable comments. 


\section{References}

Aarhus, K. (2000). Office location decisions, modal split and the environment: The ineffectiveness of Norwegian land-use policy. Journal of Transport Geography, 8(4), 287-294.

Bamberg, S. (2006). Is a residential relocation a good opportunity to change people's travel behavior? Results from a theory-driven intervention study. Environment and Behavior, 38(6), 820-840.

Bell, D. A. (1991). Office location — city or suburbs? Travel impacts arising from office relocation from city to suburbs. Transportation, 18(3), 239-259.

Buliung, R. N., \& Kanaroglou, P. S. (2006). A GIS toolkit for exploring geographies of household activity/travel behavior. Journal of Transport Geography, 14(1), 35-51.

Burke, M. I., Li, T., \& Dodson, J. (2011). What happens when government workers move to the suburbs? Impact on transport of planned decentralization of employment in Brisbane, Australia.

Carpentier, S., \& Gerber, P. (2009). Les déplacements domicile-travail: En voiture, en train ou à pied? Retrieved from https://halshs.archives-ouvertes.fr/halshs-01132986/document

Cervero, R., \& Landis, J. (1992). Suburbanization of jobs and the journey to work: A submarket analysis of commuting in the San Francisco Bay Area. Journal of Advanced Transportation, 26(3), 275-297.

Cervero, R., \& Wu, K.-L. (1998). Sub-centering and commuting: Evidence from the San Francisco Bay Area, 1980-90. Urban Studies, 35(7), 1059-1076.

Chilla, T., \& Schulz, C. (2015). Spatial development in Luxembourg: Mimetic evolution or emergence of a new planning culture? European Planning Studies, 23(3), 509-528.

Drevon, G., Gerber, P., Klein, O., \& Enaux, C. (2016). Measuring functional integration by identifying the trip chains and the profiles of cross-border workers: Empirical evidences from Luxembourg. Journal of Borderlands Studies. doi: 10.1080/08865655.2016.1257362

Epstein, D. (2010). Lévolution de la vitesse de déplacement domicile-travail au Luxembourg de 1960 à nos jours. Les Cahiers Du CEPS/INSTEAD, p. num. 2010-17, 20 p.

Gong, J. (2002). Clarifying the standard deviational ellipse. Geographical Analysis, 34(2), 155-167.

Gordon, P., \& Richardson, H. W. (1997). Are compact cities a desirable planning goal? Journal of the American Planning Association, 63(1), 95-106.

Hanssen, J. U. (1995). Transportation impacts of office relocation: A case study from Oslo. Journal of Transport Geography, 3(4), 247-256.

Klein, S. (2010). Les transports en commun au Luxembourg en 2006-2007. Les Cahiers Du CEPS/ INSTEAD, p. Cahier n'2010-11, 20 p.

Kwan, M.-P. (1998). Space-time and integral measures of individual accessibility: A comparative analysis using a point-based framework. Geographical Analysis, 30(3), 191-216.

Lefever, D. W. (1926). Measuring geographic concentration by means of the standard deviational ellipse. American Journal of Sociology, 32(1), 88-94.

Li, T., Burke, M., \& Dodson, J. (2016). Transport impacts of government employment decentralization in Australian city - Testing scenarios using transport simulation. Socio-Economic Planning Sciences, $58,63-71$.

Mitchell, A. (2005). The ESRI guide to GIS analysis, Volume 2: Spatial measurements and statistics. Redlands, CA: ESRI Press.

Naess, P., \& Sandberg, S. L. (1996). Workplace location, modal split and energy use for commuting trips. Urban Studies, 33(3), 557-580.

Perchoux, C., Kestens, Y., Thomas, F., Hulst, A. V., Thierry, B., \& Chaix, B. (2014). Assessing patterns of spatial behavior in health studies: Their socio-demographic determinants and associations with transportation modes (the RECORD Cohort Study). Social Science \& Medicine, 119, 64-73. 
Rau, H., \& Manton, R. (2016). Life events and mobility milestones: Advances in mobility biography theory and research. Journal of Transport Geography, 52, 51-60.

Redmond, L. S., \& Mokhtarian, P. L. (2001). The positive utility of the commute: Modeling ideal commute time and relative desired commute amount. Transportation, 28(2), 179-205.

Schoenduwe, R., Mueller, M. G., Peters, A., \& Lanzendorf, M. (2015). Analyzing mobility biographies with the life course calendar: A retrospective survey methodology for longitudinal data collection. Journal of Transport Geography, 42, 98-109.

Schönfelder, S., \& Axhausen, K. W. (2003). Activity spaces: Measures of social exclusion? Transport Policy, 10(4), 273-286.

Sprumont, F., Viti, F., Caruso, G., \& König, A. (2014). Workplace relocation and mobility changes in a transnational metropolitan area: The case of the University of Luxembourg. Transportation Research Procedia, 4, 286-299.

STATEC. (2016). Emploi et chômage par mois 2000 - 2016. Retrieved from http://www.statistiques. public.lu/

TomTom Traffic Index. (2015). Retrieved from https://www.tomtom.com/en_gb/trafficindex/

Van Acker, V., van Wee, B., \& Witlox, F. (2010). When transport geography meets social psychology: Toward a conceptual model of travel behavior. Transport Reviews, 30(2), 219-240

Vale, D. S. (2013). Does commuting time tolerance impede sustainable urban mobility? Analyzing the impacts on commuting behavior as a result of workplace relocation to a mixed-use center in Lisbon. Journal of Transport Geography, 32, 38-48.

Walther, O., \& Dautel, V. (2010). Intra-regional employment growth in Luxembourg (1994-2005). Geografiska Annaler. Series B, Human Geography, 92(1), 45-63.

Yuill, R. S. (1971). The standard deviational ellipse: An updated tool for spatial description. Geografiska Annaler. Series B, Human Geography, 53(1), 28-39.

\section{Appendices}

Appendices 1 and 2 are available online at https://www.jtlu.org/index.php/jtlu/article/view/1123. 